\title{
Do interventions to improve adherence to antiretroviral therapy recognise diversity? A systematic review
}

Nidhi Wali, MA, Humanitarian and Development Research Initiative, School of Social

Sciences and Psychology, Western Sydney University

Andre Renzaho, PhD, MPH, B. Nutr. \& Diet., School of Social Sciences and Psychology,

Western Sydney University

Xia Wang, MSc, School of Pharmacy, University of East Anglia

Bethany Atkins, MA, School of Pharmacy, University of East Anglia

Debi Bhattacharya, PhD, BPharm, School of Pharmacy, University of East Anglia

\section{Correspondence to:}

Debi Bhattacharya, fax: +44(0)1603 592003, phone: $+44(0) 1603593391$

email: d.bhattacharya@uea.ac.uk

ORCID iD: https://orcid.org/0000-0003-3024-7453

Twitter handle: @DebiBhattachar

The research was funded by a grant from the University of East Anglia to support crossdisciplinary research.

Running head: Diversity of adherence trials 


\begin{abstract}
People living with HIV (PLWH) are often culturally and linguistically diverse populations; these differences are associated with differing barriers to antiretroviral therapy (ART) adherence. Cultural competence measures the extent to which trial design recognises this diversity. This systematic review aimed to determine whether adherence trial participants represent the diversity of PLWH.
\end{abstract}

Randomised Controlled Trials in Organisation for Economic Co-operation and Development countries to improve ART adherence were eligible. We searched MEDLINE, EMBASE, and Cochrane Database of Systematic Reviews. For all included trials, we searched for their development, testing and evaluation studies. We compared trial participant characteristics with nationally reported PLWH data. We appraised trial cultural competence against ten criteria; scoring each criterion as 0,1 or 2 indicating cultural blindness, pre-competence or competence respectively.

For 80 included trials, a further 13 studies presenting development/testing/evaluation data for the included trials were identified. Only one of the 80 included studies reported trial participants representative of the country's population of PLWH. The median (IQ) cultural competence score was $2.5(1.0,4.0)$ out of 20 . HIV adherence trial participants are not reflective of the population with HIV, which may be due to limited adoption of culturally competent research methods.

Key words: HIV; generalisability; diversity; trial reporting guidelines; transferability 


\section{Introduction}

Sub-optimal adherence to Antiretroviral treatment (ART) in people living with HIV (PLWH) has led to numerous adherence interventions (Kanters et al., 2017). Implementation of these interventions into routine care has been limited (Simoni et al., 2017) and may reflect poor acceptability and feasibility in the real world environment (de Bruin et al., 2010).

PLWH are often culturally and linguistically diverse populations (Hernando et al., 2015) with differing barriers to ART adherence (Croome, et al. 2017; Shubber et al., 2016). Socio-cultural factors such as low levels of social support, poor health/medical knowledge, culturally mediated negative beliefs about ART and stigmatisation are all associated with sub-optimal ART adherence (Ammassari et al., 2002). In most Organisation for Economic Co-operation and Development (OECD) countries, HIV/AIDS disproportionately affect migrants. Whilst accounting for less than $16 \%$ of the European Union population, $40 \%$ of PLWH in the European Union are migrants (Hernando et al., 2015). Similar disproportionate representation is observed in the USA (Prosser, Tang, \& Hall, 2012). ART adherence interventions should therefore recognise this cultural diversity during the research development, evaluation and implementation phases.

Trial reporting guidelines specifying the need for baseline demographics do not adequately reflect the complexities of cultural identity and how it is socially constructed in language (Schulz et al., 2010). However, these demographics are the best available data for assessing cultural diversity.

Cultural competence is as an "ongoing capacity of healthcare systems, organizations, and professionals to provide for diverse patient populations high-quality care that is safe, patient and family centred, evidence based, and equitable" (National Quality Forum 2008). Gibbs et al. (2007) report a cultural competence research framework comprising nine criteria spanning 
the processes of study design, recruitment, analysis and dissemination all being in partnership with the target population. This framework has been applied to evaluate observational studies (Riggs et al., 2014) but it is yet to be applied to randomised controlled trials (RCT). The need for brevity in RCT trial reporting may prohibit full characterisation of intervention development and subsequent evaluation. However, facilities for publishing protocols, feasibility, pilot and process evaluation studies allows ample opportunity for researchers to report additional data. Trials, as a component of CONSORT reporting, routinely provide the demographic characteristics of participants (Schulz et al. 2010) thus providing the minimum necessary data to evaluate the extent to which participants reflect the population with HIV.

This study aimed to characterise the extent to which ART adherence intervention trials conducted in OECD countries are designed and implemented in recognition of the diversity of the population for which the intervention is intended.

\section{Materials and Methods}

\section{Phase 1. Identifying relevant RCTs}

The study followed the Preferred Reporting Items for Systematic reviews and Meta-Analysis (Moher et al., 2009) and was registered in PROSPERO (CRD42017077501). RCTs reported in English of any intervention to improve adherence to ART by adults were eligible. The review included all health care settings in OECD countries. We limited to OECD countries through manual searches of identified RCTs. We excluded studies using real-time monitoring for measuring adherence as they are subject to reactivity bias and thus less likely to be used to inform policy and practice.

RCTs were identified through searches of MEDLINE, EMBASE, and Cochrane Database of Systematic Reviews. Supplementary file 1 provides the search strategy adapted for each 
database to accommodate different syntax rules. Two researchers (XW and NW) independently screened all titles and abstracts for relevance using an abstract screening tool (supplementary file 2). All retrieved articles were assessed for eligibility. Conflicts were resolved by discussion between the two reviewers and any disagreement by adjudication of a third independent reviewer (DB).

\section{Phase 2. Identifying development, testing and evaluation studies related to included RCTs}

Articles were eligible if they reported development, feasibility/piloting, evaluation or implementation of one or more intervention components from RCTs included at phase 1 . We used the UK Medical Research Council definition of these research phases to determine eligibility (Craig et al., 2008).

BA undertook individualised searches for every author of RCTs included from phase 1. This identified any related publications on Pubmed, ResearchGate and Google Scholar. BA and DB independently reviewed all retrieved articles for eligibility.

\section{Data extraction}

An Excel data extraction sheet was developed for capturing participant socio-demographic characteristics and trial conduct data. Data were extracted verbatim thus terminologies for socio-demographic characteristics may have been specific to the country in which the study was conducted. Data were independently extracted by (XW, NW and BA); any discrepancies resolved by a third reviewer (DB).

\section{Quality assessment}

Definitions for each of the nine Gibbs et al. criteria for culturally competent research were adapted by the research team to better reflect the language of RCTs. The criterion ‘analysis/evaluation' was split into two separate criteria for RCT conduct (Figure 1). 
[Figure 1 about here]

\section{Data analysis}

For each included study, if the reporting of socio-demographic characteristics enabled them to be attributed to individual countries, then these were compared with the sociodemographic characteristics of the country's population with HIV, providing that these data were publicly available. This enabled us to establish the extent to which the trial population represented the diversity of the PLWH population.

For each of the ten criteria, XW and NW independently rated included studies on a scale of 0 to 2 for each of the ten criteria (Figure 1); any disagreements were referred to DB for arbitration. Lack of reporting prohibits the reader from evaluating the likely applicability of the research findings for any given population hence this was categorised as 0 .

\section{Results}

Figure 2 provides the flow of studies; of the 80 studies retained in this systematic review, 66 $(83 \%)$ were conducted in the USA, three in France (4\%), two in Spain $(2.5 \%)$, and one each in Canada (1\%), Holland (1\%) and Switzerland (1\%). The remaining six (8\%) were conducted in multiple OECD countries. Adherence interventions were wide ranging and included reminder devices, electronic communication such as short message service and face-to-face consultations. From the 13 relevant articles identified in phase 2 searches, five focussed on post-trial evaluation, however only one of these studies contributed extra data for assessing cultural competence (Garland et al., 2007). All eight of the trial developmental studies from the phase 2 searches contributed extra information to assess cultural competence. They provided details of early engagement and/or intervention refinement resulting from engaging 
with the target population (Altice et al., 2004; Dilorio et al., 2003; Golin et al., 2016; Ingersoll et al., 2014; Macalino et al., 2004; Moore et al., 2013; van Servellen et al., 2003; Wohl et al., 2004).

[Figure 2 about here]

\section{Trial participants}

Table 1 provides the extent to which trial participants represent the country's population prescribed ART. Only one study was representative based on the reported characteristics, however, this study did not report sexual orientation and/or mode of HIV acquisition (Enriquez et al., 2015). Supplementary file 3 provides details of trial participant characteristics. Only 35 (43\%) studies reported sexual orientation and for eight of these studies, men who have sex with men contributed over $70 \%$ of participants (Antoni et al., 2006; de Bruin et al., 2010; Johnson et al., 2011; Kurth et al., 2014; Ramirez-Garcia \& Côté, 2012; Roth et al., 2012; Safren et al., 2001; Wagner et al., 2013).

[Table 1 about here]

\section{Cultural competence assessment}

No studies achieved the maximum cultural competence score of twenty. The median (interquartile) cultural competence score was $2.5(1.0,4.0)$. Table 1 provides the summary scores for each study's cultural competence assessment. The highest score was 12 and this was the only study reporting participants representative of the country's HIV population. Figure 3 
illustrates the limited number of studies adopting culturally competent methods across the ten criteria. Studies generally performed better for the criteria of 'identifying the target population' and 'developing the intervention' whilst reported involvement of the target population in disseminating trial findings was absent.

[Figure 3 about here]

\section{Forming partnerships and defining research questions}

Limited patient involvement was reported during the stage of conceiving the research ideas. Figure 2 indicates slightly better performance in forming partnerships relative to defining research questions. Three studies were rated as culturally competent as they involved participants during the design stage to consider their preferences (Ingersoll et al., 2015; Ingersoll et al., 2011; Safren et al., 2012). One trial was rated as culturally pre-competent because even though they did not reach out to the target community, the research team comprised PLWH and they were involved in the design, implementation and evaluation of the trial (Enriquez et al., 2015).

\section{Identifying the target population}

A medical setting such as HIV clinics were the recruitment source for $54(68 \%)$ trials. These trials were characterised as pre-competent as the involvement of health care providers in the recruitment process may introduce bias. Recruitment from community settings including community outreach (Antoni et al., 2006) and primary care providers (Collier et al., 2005; Ingersoll et al., 2011; Kalichman et al., 2011; Kurth et al., 2014; Parsons et al., 2007; Pellowski et al., 2016; Remien et al., 2005; Safren et al., 2016; Safren et al., 2003) was adopted in ten studies whilst nine studies adopted multiple strategies including various combinations of HIV 
clinics, primary care providers, and local advertisements (Dale et al., 2016; Duncan et al., 2012; Enriquez et al., 2015; Gwadz et al., 2015; Huhn et al., 2017; Johnson et al., 2011; Johnson et al., 2007; Safren et al., 2001; Williams et al., 2006).

\section{Appointing staff}

Representation of the target population in the research team was limited to seven (9\%) studies. For five studies, PLWH were directly involved in intervention delivery (Enriquez et al., 2015; Gwadz et al., 2015; Simoni et al., 2007; Simoni et al., 2009; Williams et al., 2006). For the remaining two studies, research teams included community representatives and relevant bilingual workers guiding the research conduct (Floris-Moore et al., 2016; van Servellen et al., 2005).

\section{Recruitment of sample}

Most of the studies included recruitment restrictions such as 'must provide written informed consent'. Two studies translated consent materials to make them accessible to the target populations of both English and Spanish speakers (Enriquez et al., 2015; Wohl et al., 2006). One study explicitly commented that their driver for excluding potential participants who could not read and speak English was the challenge of creating research and intervention materials for diverse populations (de Bruin et al., 2010).

\section{Data collection}

The data collection processes for only $22(27 \%)$ studies catered to a culturally and linguistically diverse population. These included translating project materials (Collier et al., 2005; Samet et al., 2005); engaging bilingual community workers for data collection (Garland et al., 2007; van Servellen et al., 2005; Williams et al., 2006; Wohl et al., 2006); flexible session times (Kurth et al., 2014; Reynolds et al., 2008; Robbins et al., 2013); tailoring intervention activities based 
on individual patient needs (Antoni et al., 2006; Gwadz et al., 2015); flexible locations (Garland et al., 2007; Johnson et al., 2011; Johnson et al., 2007; Macalino et al., 2007; Roth et al., 2012); providing male-female facilitator pairs (Kalichman et al., 2011); and flexible intervention delivery methods (Murphy et al., 2007; Pellowski et al., 2016). Others provided childcare (Holstad et al., 2011); matched project peers to participants on the basis of ethnicity, sex, and sexual orientation (Simoni et al., 2007; Simoni et al., 2009); and included patient participation in the intervention (Moore et al., 2015).

\section{Development of intervention}

Almost half of the trials (53\%) customised the intervention for the target population such as varying intervention content (Johnson et al., 2011; Johnson et al., 2007; Kalichman et al., 2011; Kurth et al., 2014; Mannheimer et al., 2006; Parsons et al., 2007; Wagner et al., 2006; Wagner et al., 2013; Weber et al., 2004), location (Garland et al., 2007; Macalino et al., 2007; Roth et al., 2012) and frequency (de Bruin et al., 2010; Dilorio et al., 2008; Tuldra et al., 2000) according to participant preference or feedback. Enriquez et al. (2015) partnered PLWH with the researchers to translate a nurse-led intervention to a peer-led format (Enriquez et al., 2015). Other studies tailored the intervention for participants with lower health literacy skills (Pellowski et al., 2016; Rawlings et al., 2003). Several studies included consultation with patients (Robbins et al., 2013; Safren et al., 2016; Simoni et al., 2007; Simoni et al., 2009) and evaluation mechanisms to inform the next stage of the intervention (Holzemer et al., 2006). Preliminary needs assessment of participants (Wohl et al., 2017) and co-designing intervention materials were reported Moore et al (2015). Other cultural considerations were translation of written materials (Collier et al., 2005) and bilingual community workers (van Servellen et al., 2005).

\section{Analysis and Evaluation}


Two studies reported involving the target population in data analysis (Enriquez et al., 2015) (Macalino et al., 2007). Eight studies invited feedback from participants, primarily using posttrial intervention satisfaction surveys (Arribas et al., 2017; Rathbun et al., 2005; de Bruin et al., 2010; Garland et al., 2007; Himelhoch et al., 2017; Ingersoll et al., 2015; Ingersoll et al., 2011; Kurth et al., 2014). Some conducted post-trial evaluations with staff involved in intervention delivery (de Bruin et al., 2010; Himelhoch et al., 2017).

\section{Dissemination}

No studies reported disseminating findings back to the participants or target population.

\section{Discussion}

This review confirms that most HIV adherence trial participant populations are not representative of the target population. Notable differences are lower representation of ethnic minorities, females and heterosexual males. As differing sociodemographic factors are associated with differing barriers to ART adherence (Shubber et al., 2016), trial findings should be interpreted with caution when considering implementation into the real-world environment. The review also demonstrates that it is feasible to evaluate the cultural competence of RCTs but trial reporting quality prohibits comprehensive evaluation.

Cultural competence criteria align better with feasibility and process evaluation rather than RCT reporting standards (Schulz et al., 2010). However, few studies of these types were identified in this review. Due to inadequate reporting, we are therefore unable to conclusively state that trials are not adopting culturally competent methods. The limited diversity observed in trial participants, however, supports the conclusion that trials are failing to adopt culturally competent methods. Poor reporting also prohibits commissioners evaluating the extent to which trial findings are generalisable to their population. This may have contributed to the 
limited adoption of novel adherence interventions into routine care (de Bruin et al., 2010; Simoni et al., 2017).

Our synthesis of studies spanning 17 years indicates no observable trend in either improvement or decline in reporting of culturally competent research methods. A range of OECD countries are represented but the majority of studies were conducted in the USA. The general disproportionately high representation of males in the USA trials with lower cultural competence scores is of concern particularly as the rate of females diagnosed with HIV has shown a smaller decline than males (Centers for Disease Control and Prevention, 2017).

Whilst characteristics relating to ethnicity, gender, sexuality and class specified in CONSORT criteria (Schulz et al., 2010) do not adequately reflect the complexities of cultural identity, there is limited reporting of even these characteristics. The message regarding fulfilling CONSORT standards may need strengthening. This may be achieved by specifying the minimum characteristics reported for behavioural intervention studies.

The relatively good performance of most studies for identifying the target population and data sources was due to using the clinical environment for recruitment and data collection. As the target population is people prescribed ART and HIV clinic attendance is a pre-requisite for receiving ongoing ART treatment, this provides a relatively comprehensive sampling frame for recruitment. In contrast, few studies achieved trial participants representative of the country's population diagnosed with HIV in terms of ethnicity and sex; poverty of reporting precludes drawing conclusions regarding representation in terms of sexual orientation, mode of HIV acquisition and migrant status. As the procedure for identifying the target population was largely appropriate, the poor representation of the population with HIV may be a facet of inadequate research design across other criteria leading to certain populations declining trial participation. 
Few studies engaged the target population to develop the research questions and intervention. This can result in misaligned questions and sub-optimal intervention design (Gibbs, 2008) due to insufficient researcher understanding of the problem (Brett et al., 2014).

Social, cultural and personal differences influence the balance of power and hierarchy between the researcher and those being researched, especially in terms of intersectionality (DeVault and Gross, 2012). Consequently, hierarchical relationship between patients and healthcare team members who were mainly used for recruitment purposes introduces potential for consent bias (Nnaji et al., 2018). This may explain the observed poor representation of females and migrants (Hughson et al., 2016). Bias in recruitment processes may have been further compounded by the limited evidence of tailored consent processes such as language translations (Hunt \& de Voogd, 2007). Incongruously, several studies reported translation of material and multi-lingual research staff for data collection processes. This discordance may reflect inadequate reporting rather than poor trial methods. Adherence to international guidelines for reporting patient and public involvement (Staniszewska et al., 2017) would enable confirmation of the extent to which the target audience were involved in the design, conduct and reporting of the research, however no studies acknowledged this guidance. Whilst the reasonable level of target audience involvement in designing and tailoring interventions is encouraging, approaches were far removed from the growing co-design literature that positions end users as integral to the innovation process (Bate \& Robert, 2006).

A dissemination approach that garners support from the target patient/public population provides a driving force for implementation (Shippee et al., 2015). The almost non-existent presence of patients prescribed ART or their representatives in the analysis, evaluation and dissemination processes may therefore provide some explanation for the limited implementation of interventions (de Bruin et al., 2010; Simoni et al., 2017). 
Assessing the cultural competence of HIV adherence trials or any RCT is innovative. Implications for future research are that culturally competent research methods should be adopted. This required change may be supported by refining trial reporting standards and evaluating the cultural competence of trial methods. 


\section{References}

Andrade, A. S., McGruder, H. F., Wu, A. W., Celano, S. A., Skolasky, R. L. Jr., Selnes, O. A., Huang, I. C., McArthur, J. C. (2005). A Programmable Prompting Device Improves Adherence to Highly Active Antiretroviral Therapy in HIV-Infected Subjects with Memory Impairment. Clinical Infectious Diseases, 41(6), 875-882.

Alsan, M., Beshears, J., Armstrong, W., Choi, J. J., Madrian, B. C., Nguyen, M. L. T.,. . Marconi, V. C. (2017). A commitment contract for virologic suppression in poorly adherent patients with HIV/AIDS. AIDS, 31(12), 1765-1769.

Altice, F. L., Maru, D. S.-R., Bruce, R. D., Springer, S. A., \& Friedland, G. H. (2007). Superiority of Directly Administered Antiretroviral Therapy over Self-Administered Therapy among HIVInfected Drug Users: A Prospective, Randomized, Controlled Trial. Clinical infectious diseases: an official publication of the Infectious Diseases Society of America, 45(6), 770778. doi:10.1086/521166

Altice, F. L., Mezger, J. A., Hodges, J., Bruce, R. D., Marinovich, A., Walton, M., . . Friedland, G. H. (2004). Developing a directly administered antiretroviral therapy intervention for HIVinfected drug users: implications for program replication. Clin Infect Dis, 38 Suppl 5, S376387. doi:10.1086/421400

Ammassari, A., Trotta, M. P., Murri, R., Castelli, F., Narciso, P., Noto, P., . . Antinori, A. (2002). Correlates and predictors of adherence to highly active antiretroviral therapy: overview of published literature. J Acquir Immune Defic Syndr, 31 Suppl 3, S123-127.

Antoni, M. H., Carrico, A. W., Duran, R. E., Spitzer, S., Penedo, F., Ironson, G., . . . Schneiderman, N. (2006). Randomized Clinical Trial of Cognitive Behavioral Stress Management on Human Immunodeficiency Virus Viral Load in Gay Men Treated With Highly Active Antiretroviral Therapy. Psychosomatic Medicine January/February, 68(1), 143-151.

Arribas, J. R., DeJesus, E., van Lunzen, J., Zurawski, C., Doroana, M., Towner, W., . . Nguyen, T. (2017). Simplification to single-tablet regimen of elvitegravir, cobicistat, emtricitabine, tenofovir DF from multi-tablet ritonavir-boosted protease inhibitor plus coformulated emtricitabine and tenofovir DF regimens: week 96 results of STRATEGY-PI. HIV Clinical Trials, 18(3), 118-125. doi:10.1080/15284336.2017.1330440

Bate, P., \& Robert, G. (2006). Experience-based design: from redesigning the system around the patient to co-designing services with the patient. Quality and Safety in Health Care, 15(5), 307-310. doi: 10.1136/qshc.2005.016527

Berg, K. M., Litwin, A., Li, X., Heo, M., \& Arnsten, J. H. (2011). Directly observed antiretroviral therapy improves adherence and viral load in drug users attending methadone maintenance clinics: A randomized controlled trial. Drug and Alcohol Dependence, 113(2), 192-199. doi:https://doi.org/10.1016/j.drugalcdep.2010.07.025

Betancourt, J. R., Green, A. R., Carrillo, J. E., \& Ananeh-Firempong, O. (2003). Defining cultural competence: a practical framework for addressing racial/ethnic disparities in health and health care. Public Health Reports, 118(4), 293-302.

Brett, J., Staniszewska, S., Mockford, C., Herron-Marx, S., Hughes, J., Tysall, C., \& Suleman, R. (2014). A Systematic Review of the Impact of Patient and Public Involvement on Service Users, Researchers and Communities. The Patient - Patient-Centered Outcomes Research, 7(4), 387-395. doi:10.1007/s40271-014-0065-0

Brunetta, J., Moreno Guillén, S., Antinori, A., Yeni, P., Wade, B., Johnson, M., . . . De-Oertel, S. (2015). Patient-Reported Outcomes After a Switch to a Single-Tablet Regimen of Rilpivirine, Emtricitabine, and Tenofovir DF in HIV-1-Positive, Virologically Suppressed Individuals: Additional Findings From a Randomized, Open-Label, 48-Week Trial. Patient - PatientCentered Outcomes Research, 8(3), 257-267. doi:10.1007/s40271-015-0123-2

Calderón, M. M., Penzak, S. R., Pau, A. K., Kumar, P., McManus, M., Alfaro, R. M., \& Kovacs, J. A. (2016). Efavirenz but Not Atazanavir/Ritonavir Significantly Reduces Atovaquone Concentrations in HIV-Infected Subjects. Clinical Infectious Diseases, 62(8), 1036-1042. doi:10.1093/cid/ciw028 
Centers for Disease Control and Prevention. (2017). HIV surveillance report, 2016; vol. 28. Retrieved from http://www.cdc.gov/hiv/library/reports/hiv-surveillance.html

Collier, A. C., Ribaudo, H., Mukherjee, A. L., Feinberg, J., Fischl, M. A., Chesney, M., \& Adult, A. C. T. G. S. T. (2005). A Randomized Study of Serial Telephone Cal Support to Inaease Adherence and Thereby Improve Virologic Outcome in Persons Initiating Antiretroviral Therapy. The Journal of Infectious Diseases, 192(8), 1398-1406.

Craig P, Dieppe P, Macintyre S, Michie S, Nazareth I, Petticrew M, et al. Developing and evaluating complex interventions: the new Medical Research Council guidance. BMJ. 2008;337:a1655.

Croome, N., Ahluwalia, M., Hughes, L. D., \& Abas, M. (2017). Patient-reported barriers and facilitators to antiretroviral adherence in sub-Saharan Africa. AIDS, 31(7), 995-1007. doi:10.1097/qad.0000000000001416

Cross, T, L., Bazron, B. J., Dennis, K. W., \& Isaacs, M. R. (1989). Towards a culturally competent system of care, 1, Washington DC: Georgetown University Child Development Center.

Dale, S. K., Traeger, L., O'Cleirigh, C., Bedoya, C. A., Pinkston, M., Wilner, J. G., . . . Safren, S. A. (2016). Baseline Substance Use Interferes with Maintenance of HIV Medication Adherence Skills. AIDS Patient Care \& STDs, 30(5), 215-220. doi:10.1089/apc.2015.0340

de Bruin, M., Hospers, H. J., van Breukelen, G. J., Kok, G., Koevoets, W. M., \& Prins, J. M. (2010). Electronic monitoring-based counseling to enhance adherence among HIV-infected patients: A randomized controlled trial. Health Psychology, 29(4), 421-428.

DeVault, M. L. and Gross, G. (2012). Feminist interviewing: Experience, talk, and knowledge in Hesse-Biber, S. N. Handbook of feminist research: theory and praxis, $2^{\text {nd }}$ ed. SAGE Publications.

Dilorio, C., Resnicow, K., McDonnell, M., Soet, J., McCarty, F., \& Yeager, K. (2003). Using motivational interviewing to promote adherence to antiretroviral medications: a pilot study. Journal of the Association of Nurses in AIDS Care, 14(2), 52-62. doi:10.1177/1055329002250996

Dilorio, C., McCarty, F., Resnicow, K., McDonnell Holstad, M., Soet, J., Yeager, K., . . . Lundberg, B. (2008). Using motivational interviewing to promote adherence to antiretroviral medications: A randomized controlled study. AIDS Care, 20(3), 273-283. doi:10.1080/09540120701593489

Doerfler, R. E., \& Goodfellow, L. (2016). Brief Exposure to Cognitive Behavioral Therapy Reduces Side-Effect Symptoms in Patients on Antiretroviral Therapy. Journal of the Association of Nurses in AIDS Care, 27(4), 455-467. doi:https://dx.doi.org/10.1016/j.jana.2016.02.010

Duncan, L. G., Moskowitz, J. T., Neilands, T. B., Dilworth, S. E., Hecht, F. M., \& Johnson, M. O. (2012). Mindfulness-Based Stress Reduction for HIV Treatment Side Effects: A Randomized, Wait-List Controlled Trial. Journal of Pain and Symptom Management, 43(2), 161-171. doi:https://doi.org/10.1016/j.jpainsymman.2011.04.007

Enriquez, M., Cheng, A. L., Banderas, J., Farnan, R., Chertoff, K., Hayes, D., . . McKinsey, D. (2015). A Peer-Led HIV Medication Adherence Intervention Targeting Adults Linked to Medical Care but without a Suppressed Viral Load. Journal of the International Association of Providers of AIDS Care, 14(5), 441-448. doi:https://dx.doi.org/10.1177/2325957414558301

Floris-Moore, M. A., Mollan, K., Wilkin, A. M., Johnson, M. A., Kashuba, A. D., Wohl, D., . . Eron, J. J. (2016). Antiretroviral activity and safety of once-daily etravirine in treatment-naive HIVinfected adults: 48-week results. Antiviral Therapy, 21(1), 55-64. doi:http://dx.doi.org/10.3851/IMP2982\%29

Garland, W. H., Wohl, A. R., Valencia, R., Witt, M. D., Squires, K., Kovacs, A., . . Weidle, P. J. (2007). The acceptability of a directly-administered antiretroviral therapy (DAART) intervention among patients in public HIV clinics in Los Angeles, California. AIDS Care, 19(2), 159-167. doi:10.1080/09540120600911428

Gibbs L, W. E., Renzaho A, Kulkens M. (2007). Moving towards increased cultural competency in public health research. In D. R. Williamson A (Ed.), Researching with communities: grounded perspectives on engaging communities in research (pp. 339-355). London: Muddy Creek Press. 
Gibbs, L., Gold, L. C., Kulkens, M., Riggs, E., Van Gemert, C. \& Waters, E. (2008). Are the potential benefits of a community-based participatory approach to public health research worth the potential cost? Just policy: a journal of Australian social policy, 47, 54-59.

Goggin, K., Gerkovich, M. M., Williams, K. B., Banderas, J. W., Catley, D., Berkley-Patton, J., . . . Clough, L. A. (2013). A Randomized Controlled Trial Examining the Efficacy of Motivational Counseling with Observed Therapy for Antiretroviral Therapy Adherence. AIDS and Behavior, 17(6), 1992-2001. doi:10.1007/s10461-013-0467-3

Golin, C. E., Knight, K., Carda-Auten, J., Gould, M., Groves, J., B, L. W., . . Wohl, D. (2016). Individuals motivated to participate in adherence, care and treatment (imPACT): development of a multi-component intervention to help HIV-infected recently incarcerated individuals link and adhere to HIV care. BMC Public Health, 16, 935. doi:10.1186/s12889-016-3511-1

Goujard, C., Bernard, N., Sohier, N., Peyramond, D., Lancon, F., Chwalow, J., . . . Delfraissy, J. F. (2003). Impact of a patient education program on adherence to HIV medication: a randomized clinical trial. J Acquir Immune Defic Syndr, 34(2), 191-194.

Gross, R., Bellamy, S. L., Chapman, J., Han, X., O'Duor, J., Palmer, S. C., . . Strom, B. L. (2013). Managed problem solving for antiretroviral therapy adherence: a randomized trial. JAMA Intern Med, 173(4), 300-306. doi:10.1001/jamainternmed.2013.2152

Gross, R., Tierney, C., Andrade, A., Lalama, C., Rosenkranz, S., Eshleman, S. H., . . Mildvan, D. (2009). Modified directly observed antiretroviral therapy compared with self-administered therapy in treatment-naive HIV-1-infected patients: a randomized trial. Arch Intern Med, 169(13), 1224-1232. doi:10.1001/archinternmed.2009.172

Gwadz, M., Cleland, C. M., Applegate, E., Belkin, M., Gandhi, M., Salomon, N., . . Mildvan, D. (2015). Behavioral intervention improves treatment outcomes among HIV-infected individuals who have delayed, declined, or discontinued antiretroviral therapy: a randomized controlled trial of a novel intervention. AIDS and behavior, 19(10), 1801-1817. doi:http://dx.doi.org/10.1007/s10461-015-1054-6

Hernando, V., Alvarez-del Arco, D., Alejos, B., Monge, S., Amato-Gauci, A. J., Noori, T., . . del Amo, J. (2015). HIV Infection in Migrant Populations in the European Union and European Economic Area in 2007-2012: An Epidemic on the Move. J Acquir Immune Defic Syndr, 70(2), 204-211. doi:10.1097/qai.0000000000000717

Hersch, R. K., Cook, R. F., Billings, D. W., Kaplan, S., Murray, D., Safren, S., . . Spencer, J. (2013). Test of a web-based program to improve adherence to HIV medications. AIDS \& Behavior, 17(9), 2963-2976. doi:10.1007/s10461-013-0535-8

Higgins, J. P. T., \& Green, S. (2009). Cochrane handbook for systematic reviews of interventions, version 5.0.2: The Cochrane Collaboration.

Himelhoch, S., Kreyenbuhl, J., Palmer-Bacon, J., Chu, M., Brown, C., \& Potts, W. (2017). Pilot feasibility study of Heart2HAART: a smartphone application to assist with adherence among substance users living with HIV. AIDS Care - Psychological and Socio-Medical Aspects of AIDS/HIV, 29(7), 898-904. doi:http://dx.doi.org/10.1080/09540121.2016.1259454

Holstad, M. M., Dilorio, C., Kelley, M. E., Resnicow, K., \& Sharma, S. (2011). Group Motivational Interviewing to Promote Adherence to Antiretroviral Medications and Risk Reduction Behaviors in HIV Infected Women. AIDS and behavior, 15(5), 885-896. doi:10.1007/s10461010-9865-y

Holzemer, W. L., Bakken, S., Portillo, C. J., Grimes, R., Welch, J., Wantland, D., \& Mullan, J. T. (2006). Testing a Nurse-Tailored HIV Medication Adherence Intervention. Nursing Research May/June, 55(3), 189-197.

Hughson, J. A., Woodward-Kron, R., Parker, A., Hajek, J., Bresin, A., Knoch, U., . . Story, D. (2016). A review of approaches to improve participation of culturally and linguistically diverse populations in clinical trials. Trials, 17(1), 263. doi:10.1186/s13063-016-1384-3

Huhn, G. D., Sigman, A., \& Livak, B. (2015). Simplification from twice-daily to once-daily darunavir/ritonavir in a randomized trial among HIV-infected persons with HIV-1 RNA suppression on antiretroviral therapy. Antiviral Therapy, 20(8), 849-854. doi:https://dx.doi.org/10.3851/IMP2962

Huhn, G. D., Tebas, P., Gallant, J., Wilkin, T., Cheng, A., Yan, M., . . McCallister, S. (2017). A Randomized, Open-Label Trial to Evaluate Switching to 
Elvitegravir/Cobicistat/Emtricitabine/Tenofovir Alafenamide Plus Darunavir in Treatment-

Experienced HIV-1-Infected Adults. JAIDS Journal of Acquired Immune Deficiency

Syndromes, 74(2), 193-200. doi:https://dx.doi.org/10.1097/QAI.0000000000001193

Hunt, L. M., \& de Voogd, K. B. (2007). Are Good Intentions Good Enough?: Informed Consent

Without Trained Interpreters. Journal of General Internal Medicine, 22(5), 598. doi:10.1007/s11606-007-0136-1

Ingersoll, K. S., Farrell-Carnahan, L., Cohen-Filipic, J., Heckman, C. J., Ceperich, S. D., Hettema, J., \& Marzani-Nissen, G. (2011). A pilot randomized clinical trial of two medication adherence and drug use interventions for HIV+ crack cocaine users. Drug and Alcohol Dependence, 116(1), 177-187. doi:https://doi.org/10.1016/j.drugalcdep.2010.12.016

Ingersoll, K. S., Dillingham, R., Reynolds, G., Hettema, J., Freeman, J., Hosseinbor, S., \& WinsteadDerlega, C. (2014). Development of a personalized bidirectional text messaging tool for HIV adherence assessment and intervention among substance abusers. $J$ Subst Abuse Treat, 46(1), 66-73. doi:10.1016/j.jsat.2013.08.002

Ingersoll, K. S., Dillingham, R. A., Hettema, J. E., Conaway, M., Freeman, J., Reynolds, G., \& Hosseinbor, S. (2015). Pilot RCT of bidirectional text messaging for ART adherence among nonurban substance users with HIV. Health Psychology, 34S, 1305-1315. doi:https://dx.doi.org/10.1037/hea0000295

Jadad, A. R., Moore, R. A., Carroll, D., Jenkinson, C., Reynolds, D. J., Gavaghan, D. J., \& McQuay, H. J. (1996). Assessing the quality of reports of randomized clinical trials: is blinding necessary? Control Clin Trials, 17(1), 1-12.

Javanbakht, M., Prosser, P., Grimes, T., Weinstein, M., \& Farthing, C. (2006). Efficacy of an Individualized Adherence Support Program with Contingent Reinforcement Among Nonadherent HIV-Positive Patients: Results From a Randomized Trial. Journal of the International Association of Physicians in AIDS Care, 5(4), 143-150. doi:10.1177/1545109706291706

Johnson, M. O., Charlebois, E., Morin, S. F., Remien, R. H., Chesney, M. A., \& the National Institute of Mental Health Healthy Living Project Team. (2007). Effects of a Behavioral Intervention on Antiretroviral Medication Adherence Among People Living With HIV: The Healthy Living Project Randomized Controlled Study. JAIDS Journal of Acquired Immune Deficiency Syndromes, 46(5), 574-580.

Johnson, M. O., Dilworth, S. E., Taylor, J. M., \& Neilands, T. B. (2011). Improving Coping Skills for Self-management of Treatment Side Effects Can Reduce Antiretroviral Medication Nonadherence among People Living with HIV. Annals of Behavioral Medicine, 41(1), 83-91. doi:10.1007/s12160-010-9230-4

Kalichman, S. C., Cherry, C., Kalichman, M. O., Amaral, C. M., White, D., Pope, H., . . Cain, D. (2011). Integrated behavioral intervention to improve HIV/AIDS treatment adherence and reduce HIV transmission. Am J Public Health, 101(3), 531-538. doi:10.2105/ajph.2010.197608

Kanters, S., Park, J. J., Chan, K., Socias, M. E., Ford, N., Forrest, J. I., . . Mills, E. J. (2017). Interventions to improve adherence to antiretroviral therapy: a systematic review and network meta-analysis. The Lancet HIV, 4(1), e31-e40. doi:https://doi.org/10.1016/S23523018(16)30206-5

Kim, S. H., Gerver, S. M., Fidler, S., \& Ward, H. (2014). Adherence to antiretroviral therapy in adolescents living with HIV: systematic review and meta-analysis. AIDS, 28(13), 1945-1956. doi:10.1097/qad.0000000000000316

Konkle-Parker Deborah, J., Erlen Judith, A., Dubbert Patricia, M., \& May, W. (2012). Pilot testing of an HIV medication adherence intervention in a public clinic in the Deep South. Journal of the American Academy of Nurse Practitioners, 24(8), 488-498. doi:10.1111/j.17457599.2012.00712.x

Kurth, A. E., Spielberg, F., Cleland, C. M., Lambdin, B., Bangsberg, D. R., Frick, P. A., . . Holmes, K. K. (2014). Computerized Counseling Reduces HIV-1 Viral Load and Sexual Transmission Risk: Findings From a Randomized Controlled Trial. JAIDS Journal of Acquired Immune Deficiency Syndromes, 65(5), 611-620. 
Levin, T. R., Klibanov, O. M., Axelrod, P., van der Berg-Wolf, M., Finley, G. L., Gray, A., ... Samuel, R. (2006). A randomized trial of educational materials, pillboxes, and mailings to improve adherence with antiretroviral therapy in an Inner City HIV clinic, 13(4).

Lucas, G. M., Mullen, B. A., Galai, N., Moore, R. D., Cook, K., McCaul, M. E., . . Rand, C. (2013). Directly Administered Antiretroviral Therapy for HIV-Infected Individuals in Opioid Treatment Programs: Results from a Randomized Clinical Trial. PLoS ONE, 8(7), 1-10. doi:10.1371/journal.pone.0068286

Macalino, G. E., Mitty, J. A., Bazerman, L. B., Singh, K., McKenzie, M., \& Flanigan, T. (2004). Modified directly observed therapy for the treatment of HIV-seropositive substance users: lessons learned from a pilot study. Clin Infect Dis, 38 Suppl 5, S393-397. doi:10.1086/421402

Macalino, G. E., Hogan, J. W., Mitty, J., Bazerman, L., DeLong, A., Loewenthal, H., . . Flanigan, T. (2007). A randomized clinical trial of community-based directly observed therapy as an adherence intervention for HAART among substance users. AIDS, 21(11), 1473-1477.

Magidson, J. F., Blashill, A. J., Safren, S. A., \& Wagner, G. J. (2015). Depressive symptoms, lifestyle structure, and ART adherence among HIV-infected individuals: a longitudinal mediation analysis. AIDS \& Behavior, 19(1), 34-40. doi:https://dx.doi.org/10.1007/s10461-014-0802-3

Mannheimer, S. B., Morse, E., Matts, J. P., Andrews, L., Child, C., Schmetter, B., . . f for the Terry Beirn Community Programs for Clinical Research on AIDS. (2006). Sustained Benefit From a Long-Term Antiretroviral Adherence Intervention: Results of a Large Randomized Clinical Trial. JAIDS Journal of Acquired Immune Deficiency Syndromes, 43 Supplement(1), S41S47.

Maru, D. S., Bruce, R. D., Walton, M., Springer, S. A., \& Altice, F. L. (2009). Persistence of Virological Benefits Following Directly Administered Antiretroviral Therapy Among Drug Users: Results From a Randomized Controlled Trial. JAIDS Journal of Acquired Immune Deficiency Syndromes, 50(2), 176-181.

Miro, J. M., Manzardo, C., Ferrer, E., Lonca, M., Guardo, A. C., Podzamczer, D., . . Gatell, J. M. (2015). Immune reconstitution in severely immunosuppressed antiretroviral-naive HIV-1infected patients starting efavirenz, lopinavir-ritonavir, or atazanavir-ritonavir plus tenofovir/emtricitabine: Final 48-week results (The Advanz-3 Trial). Journal of Acquired Immune Deficiency Syndromes, 69(2), 206-215. doi:http://dx.doi.org/10.1097/QAI.0000000000000567

Moher D, L. A., Tetzlaff J, Liberati, A., \& Altman, D. G. (2009). Preferred reporting items for systematic reviews and meta-analyses: the PRISMA statement. British Medical Journal, 339, 332-336.

Moore, D. J., Montoya, J. L., Blackstone, K., Rooney, A., Gouaux, B., Georges, S., . . T Tmarc Group, T. (2013). Preliminary Evidence for Feasibility, Use, and Acceptability of Individualized Texting for Adherence Building for Antiretroviral Adherence and Substance Use Assessment among HIV-Infected Methamphetamine Users. AIDS Res Treat, 2013, 585143. doi:10.1155/2013/585143

Moore, D. J., Poquette, A., Casaletto, K. B., Gouaux, B., Montoya, J. L., Posada, C., . . Atkinson, J. H. (2015). Individualized texting for adherence building (iTAB): improving antiretroviral dose timing among HIV-infected persons with co-occurring bipolar disorder. AIDS and behavior, 19(3), 459-471. doi:http://dx.doi.org/10.1007/s10461-014-0971-0

Murphy, D. A., Marelich, W. D., Rappaport, N. B., Hoffman, D., \& Farthing, C. (2007). Results of an Antiretroviral Adherence Intervention: STAR (Staying Healthy: Taking Antiretrovirals Regularly). Journal of the International Association of Physicians in AIDS Care, 6(2), 113124. doi:10.1177/1545109707301243

National Quality Forum. Endorsing a Framework and Preferred Practices for Measuring and Reporting Culturally Competent Care Quality. Washington DC: National Quality Forum; 2008

Nnaji, C., Boone, M., Pugnaire, M. P., Goode, T., Wellman, S., Gunn, A. R., . . Allison, J. (2018). An Innovative Simulation-based Community-engaged Intervention for Training Research Assistants in Culturally Appropriate Informed Consent. Prog Community Health Partnersh, 12(3), 247-262. doi:10.1353/cpr.2018.0049 
Parsons, J. T., Golub, S. A., Rosof, E., \& Holder, C. (2007). Motivational Interviewing and CognitiveBehavioral Intervention to Improve HIV Medication Adherence Among Hazardous Drinkers: A Randomized Controlled Trial. JAIDS Journal of Acquired Immune Deficiency Syndromes, 46(4), 443-450.

Pellowski, J. A., Kalichman, S. C., \& Grebler, T. (2016). Optimal Treatment Adherence Counseling Outcomes for People Living with HIV and Limited Health Literacy. Behavioral Medicine, 42(1), 39-47. doi:https://dx.doi.org/10.1080/08964289.2014.963006

Pence, B. W., Gaynes, B. N., Adams, J. L., Thielman, N. M., Heine, A. D., Mugavero, M. J., . . Quinlivan, E. B. (2015). The effect of antidepressant treatment on HIV and depression outcomes: results from a randomized trial. AIDS, 29(15), 1975-1986. doi:https://dx.doi.org/10.1097/QAD.0000000000000797

Perez-Molina, J. A., Rubio, R., Rivero, A., Pasquau, J., Suarez-Lozano, I., Riera, M., . . Moreno, S. (2015). Dual treatment with atazanavir-ritonavir plus lamivudine versus triple treatment with atazanavir-ritonavir plus two nucleos(t)ides in virologically stable patients with HIV-1 (SALT): 48 week results from a randomised, open-label, non-inferiority trial. Lancet Infect Dis, 15(7), 775-784. doi:10.1016/s1473-3099(15)00097-3

Perez-Molina, J. A., Rubio, R., Rivero, A., Pasquau, J., Suarez-Lozano, I., Riera, M., . . Group, G. S. (2015). Dual treatment with atazanavir-ritonavir plus lamivudine versus triple treatment with atazanavir-ritonavir plus two nucleos(t)ides in virologically stable patients with HIV-1 (SALT): 48 week results from a randomised, open-label, non-inferiority trial. The Lancet Infectious Diseases, 15(7), 775-784. doi:https://dx.doi.org/10.1016/S1473-3099(15)00097-3

Pradier, C., Bentz, L., Spire, B., Tourette-Turgis, C., Morin, M., Souville, M., . . Moatti, J.-P. (2003). Efficacy of an Educational and Counseling Intervention on Adherence to Highly Active Antiretroviral Therapy: French Prospective Controlled Study. HIV Clinical Trials, 4(2), 121131. doi:10.1310/hct.2003.4.2.007

Prosser, A. T., Tang, T., \& Hall, H. I. (2012). HIV in persons born outside the United States, 20072010. Jama, 308(6), 601-607. doi:10.1001/jama.2012.9046

Ramirez-Garcia, P., \& Côté, J. (2012). An Individualized Intervention to Foster Optimal Antiretroviral Treatment-Taking Behavior Among Persons Living With HIV: A Pilot Randomized Controlled Trial. Journal of the Association of Nurses in AIDS Care, 23(3), 220232. doi:https://doi.org/10.1016/j.jana.2011.04.003

Rathbun, C., Farmer, K. C., Stephens, J. R., \& Lockhart, S. M. (2005). Impact of an adherence clinic on behavioral outcomes and virologic response in treatment of HIV infection: A prospective, randomized, controlled pilot study. Clinical Therapeutics, 27(2), 199-209. doi:https://doi.org/10.1016/j.clinthera.2005.02.010

Rawlings, K. M., Thompson, M. A., Farthing, C. F., Brown, L. S., Racine, J., Scott, R. C., . . . Shaefer, M. S. (2003). Impact of an Educational Program on Efficacy and Adherence With a Twice-Daily Lamivudine/Zidovudine/Abacavir Regimen in Underrepresented HIV-Infected Patients. JAIDS Journal of Acquired Immune Deficiency Syndromes, 34(2), 174-183.

Remien, R. H., Stirratt, M. J., Dolezal, C., Dognin, J. S., Wagner, G. J., Carballo-Dieguez, A., . . Jung, T. M. (2005). Couple-focused support to improve HIV medication adherence: a randomized controlled trial. AIDS, 19(8), 807-814.

Reynolds, N. R., Testa, M. A., Su, M., Chesney, M. A., Neidig, J. L., Frank, I., . . AIDS Clinical Trials Group 731 and 384 Teams. (2008). Telephone Support to Improve Antiretroviral Medication Adherence: A Multisite, Randomized Controlled Trial. JAIDS Journal of Acquired Immune Deficiency Syndromes, 47(1), 62-68.

Riggs E, Gussy M, Gibbs L, et al. Assessing the cultural competence of oral health research conducted with migrant children. Community Dent Oral Epidemiol. 2014;42(1):43-52. doi:10.1111/cdoe. 12058

Robbins, G. K., Testa, M. A., Su, M., Safren, S. A., Morse, G., Lammert, S., . . Chesney, M. A. (2013). Site Nurse-Initiated Adherence and Symptom Support Telephone Calls for HIVPositive Individuals Starting Antiretroviral Therapy, ACTG 5031: Substudy of ACTG 384. HIV Clinical Trials, 14(5), 235-253. doi:10.1310/hct1405-235

Robbins, G. K., Cohn, S. E., Harrison, L. J., Smeaton, L., Moran, L., Rusin, D., . . Reynolds, N. R. (2016). Characteristics associated with virologic failure in high-risk HIV-positive participants 
with prior failure: a post hoc analysis of ACTG 5251. HIV Clinical Trials, 17(4), 165-172. doi:http://dx.doi.org/10.1080/15284336.2016.1189754

Rosen, M. I., Dieckhaus, K., McMahon, T. J., Valdes, B., Petry, N. M., Cramer, J., \& Rounsaville, B. (2007). Improved adherence with contingency management. AIDS Patient Care \& STDs, 21(1), 30-40.

Roth, A. M., Holmes, A. M., Stump, T. E., Aalsma, M. C., Ackermann, R. T., Carney, T. S., . . Inui, T. S. (2012). Can lay health workers promote better medical self-management by persons living with HIV? An evaluation of the Positive Choices program. Patient Education and Counseling, 89(1), 184-190. doi:https://doi.org/10.1016/j.pec.2012.06.010

Safren, S. A., Otto, M., Worth, J. L., Salomon, E., Johnson, W., Mayer, K., \& Boswell, S. (2001). Two strategies to increase adherence to HIV antiretroviral medication: Life-Steps and medication monitoring. Behaviour Research and Therapy, 39(10), 1151-1162. doi:https://doi.org/10.1016/S0005-7967(00)00091-7

Safren, S. A., Hendriksen, E. S., Desousa, N., Boswell, S. L., \& Mayer, K. H. (2003). Use of an online pager system to increase adherence to antiretroviral medications. AIDS Care, 15(6), 787793.

Safren, S. A., O'Cleirigh, C. M., Bullis, J. R., Otto, M. W., Stein, M. D., \& Pollack, M. H. (2012). Cognitive behavioral therapy for adherence and depression (CBT-AD) in HIV-infected injection drug users: A randomized controlled trial. Journal of Consulting and Clinical Psychology, 80(3), 404-415. doi:10.1037/a0028208

Safren, S. A., Bedoya, C. A., O'Cleirigh, C., Biello, K. B., Pinkston, M. M., Stein, M. D., . . Mayer, K. H. (2016). Cognitive behavioural therapy for adherence and depression in patients with HIV: a three-arm randomised controlled trial. The Lancet. HIV, 3(11), e529-e538. doi:https://dx.doi.org/10.1016/S2352-3018(16)30053-4

Samet, J. H., Horton, N. J., Meli, S., Dukes, K., Tripps, T., Sullivan, L., \& Freedberg, K. A. (2005). A randomized controlled trial to enhance antiretroviral therapy adherence in patients with a history of alcohol problems. Antivir Ther, 10(1), 83-93.

Schafer, J. J., Naples, J. G., Pizzi, L. T., \& Desimone, J. A. (2015). The effects of a pharmacistdelivered patient education programme on retention in human immunodeficiency virus care: A pilot study. Journal of Pharmaceutical Health Services Research, 6(2), 83-89. doi:http://dx.doi.org/10.1111/jphs. 12092

Schulz, K. F., Altman, D. G., \& Moher, D. (2010). CONSORT 2010 Statement: updated guidelines for reporting parallel group randomised trials. J Clin Epidemiol, 63. doi:10.1016/j.jclinepi.2010.02.005

Shippee, N. D., Domecq Garces, J. P., Prutsky Lopez, G. J., Wang, Z., Elraiyah, T. A., Nabhan, M., . . . Murad, M. H. (2015). Patient and service user engagement in research: a systematic review and synthesized framework. Health Expectations, 18(5), 1151-1166. doi:doi:10.1111/hex.12090

Shubber, Z., Mills, E. J., Nachega, J. B., Vreeman, R., Freitas, M., Bock, P., . . Ford, N. (2016). Patient-Reported Barriers to Adherence to Antiretroviral Therapy: A Systematic Review and Meta-Analysis. PLoS Medicine, 13(11), e1002183. doi:10.1371/journal.pmed.1002183

Simoni, J. M., Pantalone, D. W., Plummer, M. D., \& Huang, B. (2007). A randomized controlled trial of a peer support intervention targeting antiretroviral medication adherence and depressive symptomatology in HIV-positive men and women. Health Psychol, 26(4), 488-495. doi:10.1037/0278-6133.26.4.488

Simoni, J. M., Huh, D. M. S., Frick, P. A., Pearson, C. R., Andrasik, M. P., Dunbar, P. J., \& Hooton, T. M. (2009). Peer Support and Pager Messaging to Promote Antiretroviral Modifying Therapy in Seattle: A Randomized Controlled Trial. JAIDS Journal of Acquired Immune Deficiency Syndromes, 52(4), 465-473.

Simoni, J. M., Aunon, F. M., Kemp, C. G., Kutner, B. A., Ramaiya, M. K., Velloza, J., \& Yang, J. P. (2017). Implementation research on HIV adherence interventions: no time to wait. The Lancet Infectious Diseases, 17(6), 564-565. doi:10.1016/S1473-3099(17)30106-8

Slama, L., Landman, R., Assoumou, L., Benalycherif, A., Samri, A., Joly, V., . . Surgers, L. (2016). Efficacy and safety of once-daily ritonavir-boosted atazanavir or darunavir in combination with a dual nucleos(t)ide analogue backbone in HIV-1-infected combined ART (cART)-naive 
patients with severe immunosuppression: A 48 week, non-comparative, randomized, multicentre trial (IMEA 040 DATA trial). Journal of Antimicrobial Chemotherapy, 71(8), 2252-2261. doi:http://dx.doi.org/10.1093/jac/dkw103

Smith, S. R., Rublein, J. C., Marcus, C., Brock, T. P., \& Chesney, M. A. (2003). A medication selfmanagement program to improve adherence to HIV therapy regimens. Patient Educ Couns, 50(2), 187-199.

Staniszewska, S., Brett, J., Simera, I., Seers, K., Mockford, C., Goodlad, S., . . Tysall, C. (2017). GRIPP2 reporting checklists: tools to improve reporting of patient and public involvement in research. 358, 3453. doi:10.1136/bmj.j3453

Tuldra, A., Fumaz, C. R., Ferrer, M. J., Bayes, R., Arno, A., Balague, M., . . Clotet, B. (2000). Prospective randomized two-Arm controlled study to determine the efficacy of a specific intervention to improve long-term adherence to highly active antiretroviral therapy. JAIDS Journal of Acquired Immune Deficiency Syndromes, 25(3), 221-228.

van Servellen, G., Carpio, F., Lopez, M., Garcia-Teague, L., Herrera, G., Monterrosa, F., . . . Lombardi, E. (2003). Program to enhance health literacy and treatment adherence in lowincome HIV-infected Latino men and women. AIDS Patient Care STDS, 17(11), 581-594. doi:10.1089/108729103322555971

van Servellen, G., Nyamathi, A., Carpio, F., Pearce, D., Garcia-Teague, L., Herrera, G., \& Lombardi, E. (2005). Effects of a treatment adherence enhancement program on health literacy, patientprovider relationships, and adherence to HAART among low-income HIV-positive Spanishspeaking Latinos. AIDS Patient Care STDS, 19(11), 745-759. doi:10.1089/apc.2005.19.745

Wagner, G. J., Kanouse, D. E., Golinelli, D., Miller, L. G., Daar, E. S., Witt, M. D., . . Haubrich, R. H. (2006). Cognitive-behavioral intervention to enhance adherence to antiretroviral therapy: a randomized controlled trial (CCTG 578). AIDS, 20(9), 1295-1302. doi:10.1097/01.aids.0000232238.28415.d2

Wagner, G. J., Lovely, P., \& Schneider, S. (2013). Pilot controlled trial of the adherence readiness program: an intervention to assess and sustain HIV antiretroviral adherence readiness. AIDS \& Behavior, 17(9), 3059-3065. doi:10.1007/s10461-013-0550-9

Weber, R., Christen, L., Christen, S., Tschopp, S., Znoj, H., Schneider, C., . . Ledergerber, B. (2004). Effect of individual cognitive behaviour intervention on adherence to antiretroviral therapy: prospective randomized trial. Antivir Ther, 9(1), 85-95.

Weech-Maldonado, R., Elliott, M., Pradhan, R., Schiller, C., Dreachslin, J., \& Hays, R. D. (2012). Moving Towards Culturally Competent Health Systems: Organizational and Market Factors. Social science \& medicine (1982), 75(5), 815-822. doi:10.1016/j.socscimed.2012.03.053

White, B. L., Golin, C. E., Grodensky, C. A., Kiziah, C. N., Richardson, A., Hudgens, M. G., . . . Kaplan, A. H. (2015). Effect of directly observed antiretroviral therapy compared to selfadministered antiretroviral therapy on adherence and virological outcomes among HIVinfected prisoners: a randomized controlled pilot study. AIDS \& Behavior, 19(1), 128-136. doi:https://dx.doi.org/10.1007/s10461-014-0850-8

Wilkins, E. L., Cohen, C. J., Trottier, B., Esser, S., Smith, D. E., Haas, B., . . De-Oertel, S. (2016). Patient-reported outcomes in the single-tablet regimen (STaR) trial of rilpivirine/emtricitabine/tenofovir disoproxil fumarate versus efavirenz/emtricitabine/tenofovir disoproxil fumarate in antiretroviral treatment-naive adults infected with HIV-1 through 48 weeks of treatment. AIDS Care, 28(3), 401-408. doi:https://dx.doi.org/10.1080/09540121.2015.1096890

Williams, A. B., Fennie, K. P., Bova, C. A., Burgess, J. D., Danvers, K. A., \& Dieckhaus, K. D. (2006). Home visits to improve adherence to highly active antiretroviral therapy: a randomized controlled trial. JAIDS Journal of Acquired Immune Deficiency Syndromes, 42(3), 314-321. doi:10.1097/01.qai.0000221681.60187.88

Wohl, A. R., Garland, W. H., Squires, K., Witt, M., Larsen, R., Kovacs, A., . . Weidle, P. J. (2004). The feasibility of a community-based directly administered antiretroviral therapy program. Clin Infect Dis, 38 Suppl 5, S388-392. doi:10.1086/421401

Wohl, A. R., Garland, W. H., Valencia, R., Squires, K., Witt, M. D., Kovacs, A., . . Weidle, P. J. (2006). A randomized trial of directly administered antiretroviral therapy and adherence case management intervention. Clin Infect Dis, 42(11), 1619-1627. doi:10.1086/503906 
Wohl, D. A., Bhatti, L., Small, C. B., Edelstein, H., Zhao, H. H., Margolis, D. A., . . Shaefer, M. S. (2016). The ASSURE study: HIV-1 suppression is maintained with bone and renal biomarker improvement 48 weeks after ritonavir discontinuation and randomized switch to abacavir/lamivudine+atazanavir. HIV Medicine, 17(2), 106-117.

doi:http://dx.doi.org/10.1111/hiv.12281

Wohl, D. A., Golin, C. E., Knight, K., Gould, M., Carda-Auten, J., Groves, J. S., . . Flynn, P. M. (2017). Randomized Controlled Trial of an Intervention to Maintain Suppression of HIV Viremia After Prison Release: The imPACT Trial. JAIDS Journal of Acquired Immune Deficiency Syndromes, 75(1), 81-90. doi:https://dx.doi.org/10.1097/QAI.0000000000001337 


\section{Assessment criteria}

The following ten criteria for culturally competent research were used to assess the quality of included studies:

\section{Forming partnerships}

Did the researchers work through gatekeepers to establish relationships with the target population?

\section{Defining research questions}

Was the intervention identified and initiated in consultation with the target population?

\section{Identifying the target population and data sources}

Did the research team frame data collection to facilitate the target population?

\section{Appointing staff}

Does the research team include representation of the target population?

\section{Recruitment sample}

Was the consent process tailored for the target population including awareness of within cultural variations?

\section{Data collection}

Was the data collection process tailored for the target population?

\section{Development of intervention}

Were the target population involved in the development/customisation of the intervention?

8. Analysis

Were research team members representing the target population involved in the analysis and interpretation of data?

\section{Evaluation}

Was there feedback from participants to confirm interpretation of the results?

\section{Reporting/Disseminating findings}

Did dissemination allow the target population to discuss trial findings and generate solutions?

\section{Rating}

These criteria were rated on a scale of 0 to 2 as follows:

- Awarded 0 if - Culturally blind, which describes methodological approaches underpinned by the belief that neither colour nor culture influence behaviour and that all people are the same

- Awarded 1 if - Culturally pre-competent, which describes approaches recognising that the dominant race or culture of a country is not universally applicable but fails to fully attend to cultural differences

- Awarded 2 if - Cultural competent, which describes approaches recognising the cultural diversity of the intended population

Criteria were adapted from Gibbs, et al. (2007)

Operational definition adapted from (Cross, Bazron, Dennis and Isaacs (1989). 
Figure 1. Flowchart of study selection process

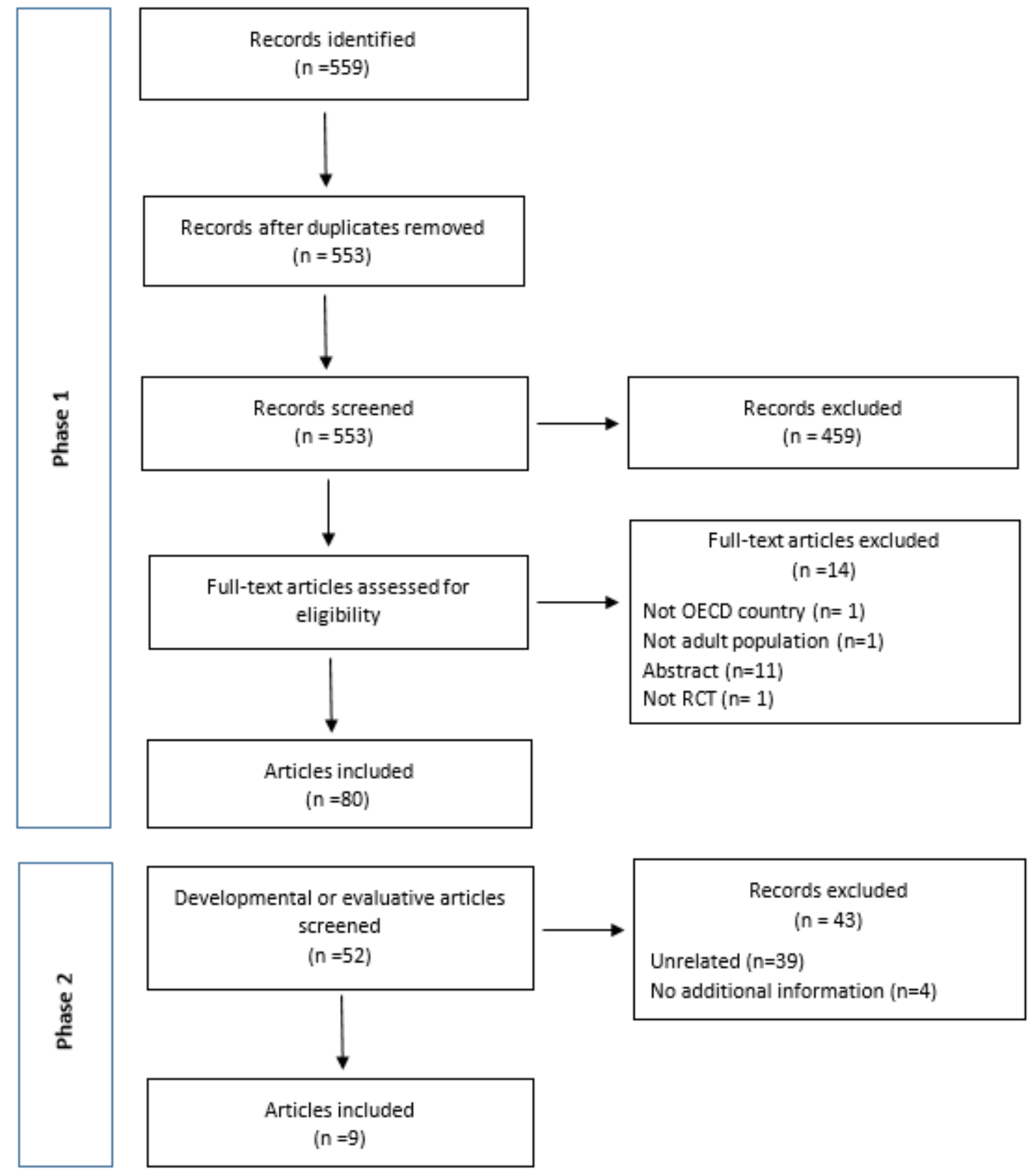


Figure 2. Performance of studies across cultural competence assessment criteria

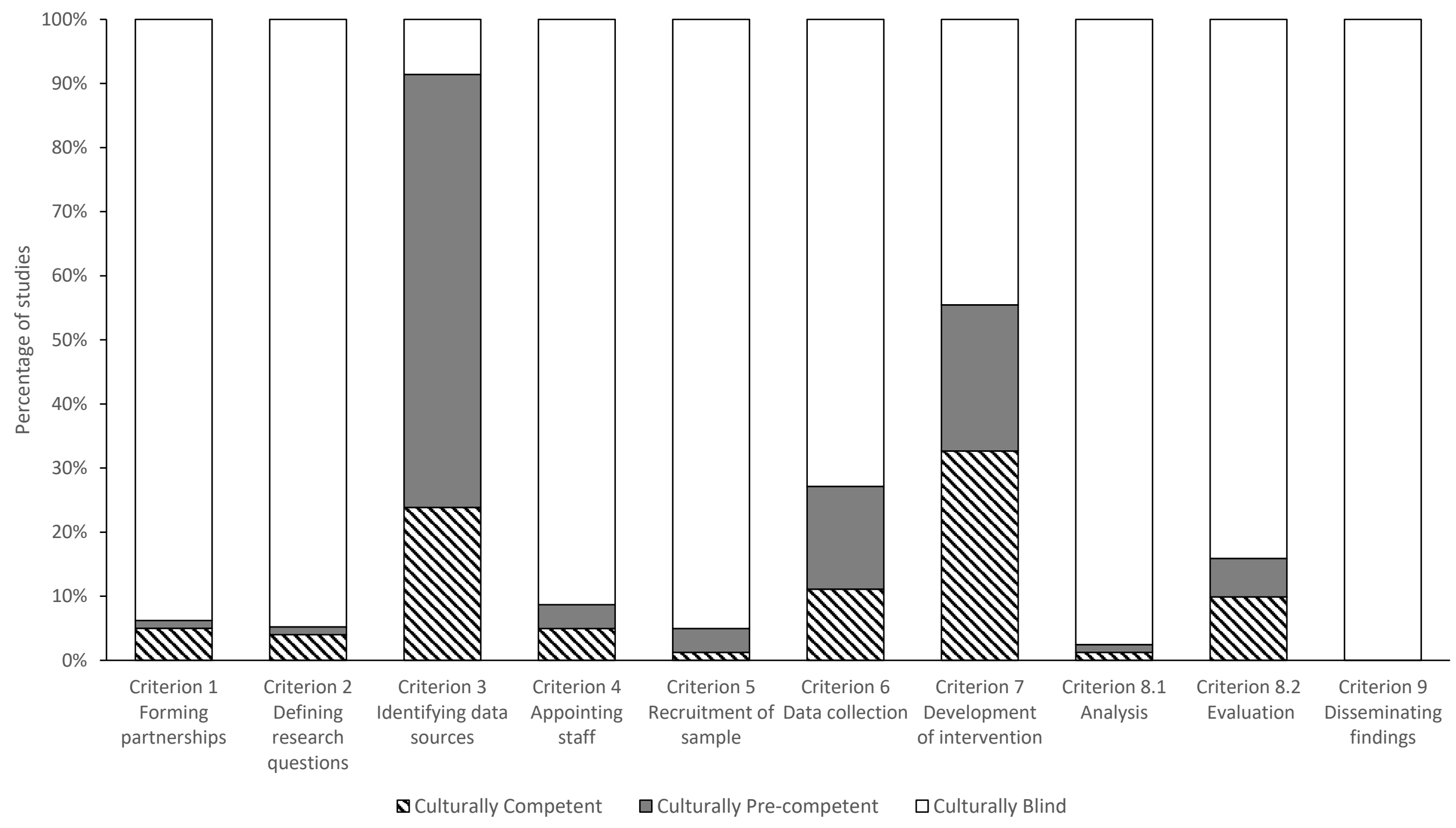




\begin{tabular}{|c|c|c|c|c|c|c|}
\hline First Author & $\begin{array}{l}\text { Publication } \\
\text { Year }\end{array}$ & Country & Race/Ethnicity & Sex & $\begin{array}{l}\text { Sexual Orientation and/or } \\
\text { mode of HIV acquisition }\end{array}$ & $\begin{array}{c}\text { Cultural } \\
\text { competence score* }\end{array}$ \\
\hline Enriquez, $\mathrm{M}$. & 2015 & USA & Representative & Representative & NA & 12 \\
\hline Macalino, G. E. & 2007 & USA & Not representative & Representative & NA & 7 \\
\hline Goggin, K. & 2013 & USA & Representative & Representative & Not representative & 3 \\
\hline Simoni, J. M. & 2007 & USA & Not representative & Not representative & NA & 5 \\
\hline Wohl, A. R. & 2006 & USA & Not representative & Representative & Not representative & 5 \\
\hline Levin, T. P. & 2006 & USA & Not representative & Not representative & NA & 1 \\
\hline Huhn, G. D. & 2017 & USA & Not representative & Representative & NA & 2 \\
\hline Ramirez-Garcia, P. & 2012 & Canada & Not representative & Not representative & Not representative & 3 \\
\hline Floris-Moore, M. A. & 2016 & USA & Representative & Not representative & NA & 0 \\
\hline Robbins, G. K. & 2016 & USA & Not representative & Not representative & NA & 0 \\
\hline Safren, S. A. & 2012 & USA & Not representative & Not representative & Not representative & 6 \\
\hline Safren, S. A. & 2016 & USA & Not representative & Not representative & Not representative & 3 \\
\hline Wagner, G. J. & 2006 & USA & Not representative & Representative & Not representative & 2 \\
\hline Kurth, A. E. & 2014 & USA & Not representative & Not representative & Not representative & 7 \\
\hline Remien, R. H. & 2005 & USA & Not representative & Not representative & Not representative & 2 \\
\hline Lucas, G. M. & 2013 & USA & Not representative & Not representative & NA & 1 \\
\hline Berg, K. M. & 2011 & USA & Not representative & Not representative & NA & 1 \\
\hline Perez-Molina, J. A. & 2015 & Spain & 79\% Native Population & Not representative & Not representative & 1 \\
\hline Calderón, M. M. & 2016 & USA & Not representative & Not representative & NA & 0 \\
\hline
\end{tabular}




\begin{tabular}{|c|c|c|c|c|c|c|}
\hline White, B. L. & 2015 & USA & Not representative & Not representative & Not representative & 1 \\
\hline Johnson, M. O. & 2007 & USA & Not representative & Representative & Not representative & 6 \\
\hline Van Servellen, G. & 2005 & USA & Not representative & Not representative & Not representative & 7 \\
\hline Slama, L. & 2016 & France & $63 \%$ European & Representative & Not representative & 0 \\
\hline Pradier, C. & 2003 & France & NA & Not representative & NA & 2 \\
\hline Javanbakht, M. & 2006 & USA & Not representative & Not representative & NA & 3 \\
\hline de Bruin, $M$. & 2010 & Holland & 100\% White & Not representative & $\begin{array}{c}\text { Int: Homosexual (78\%) } \\
\text { Control: Homosexual (67\%) }\end{array}$ & 5 \\
\hline Holstad, M. & 2011 & USA & Not representative & Not representative & Not representative & 4 \\
\hline Williams, A. B. & 2006 & USA & Not representative & Not representative & NA & 8 \\
\hline Miro, J. M. & 2015 & Spain & 65\% Spain/W Europe & Representative & Not representative & 1 \\
\hline Goujard, C. & 2003 & France & NA & Representative & NA & 1 \\
\hline Rathbun, R. C. & 2005 & USA & Not representative & Not representative & Not representative & 3 \\
\hline Rawlings, M. K. & 2003 & USA & Not representative & Not representative & Not representative & 2 \\
\hline Rosen, M. I. & 2007 & USA & Not representative & Not representative & NA & 2 \\
\hline Moore, D. J. & 2015 & USA & Not representative & Not representative & NA & 6 \\
\hline Kalichman, S. C. & 2011 & USA & Not representative & Not representative & Not representative & 5 \\
\hline Duncan, L. G. & 2012 & USA & Not representative & Not representative & NA & 2 \\
\hline Gross, R. & 2009 & USA, Puerto Rico & Not representative & Representative & NA & 1 \\
\hline Pellowski, J. A. & 2016 & USA & Not representative & Not representative & NA & 5 \\
\hline Brunetta, J. & 2015 & $\begin{array}{l}\text { Canada, Spain, Italy, } \\
\text { France, USA, UK }\end{array}$ & Not representative & Not representative & NA & 1 \\
\hline Wilkins, E. L. & 2016 & Canada, Germany, UK & Not representative & Not representative & NA & 0 \\
\hline Simoni, J. M. & 2009 & USA & Not representative & Representative & NA & 5 \\
\hline Wagner, G. J. & 2013 & USA & Not representative & Not representative & Not representative & 2 \\
\hline Himelhoch, S. & 2017 & USA & Not representative & Not representative & NA & 3 \\
\hline Konkle-Parker, D. J. & 2012 & USA & Not representative & Not representative & NA & 1 \\
\hline Tuldrà, A. & 2000 & Spain, Holland & NA & Not representative & Not representative & 2 \\
\hline Antoni, M. H. & 2006 & USA & NA & Not representative & Not representative & 3 \\
\hline
\end{tabular}


obtained from CDC HIV surveillance report and HIV/AIDS surveillance in Europe (WHO) report. *Scored as 0 (culturally blind), 1 (culturally pre-competent) or 2 (culturally competent) across 10 criteria; total score can range from 0 (culturally blind) to 20 (culturally competent). 